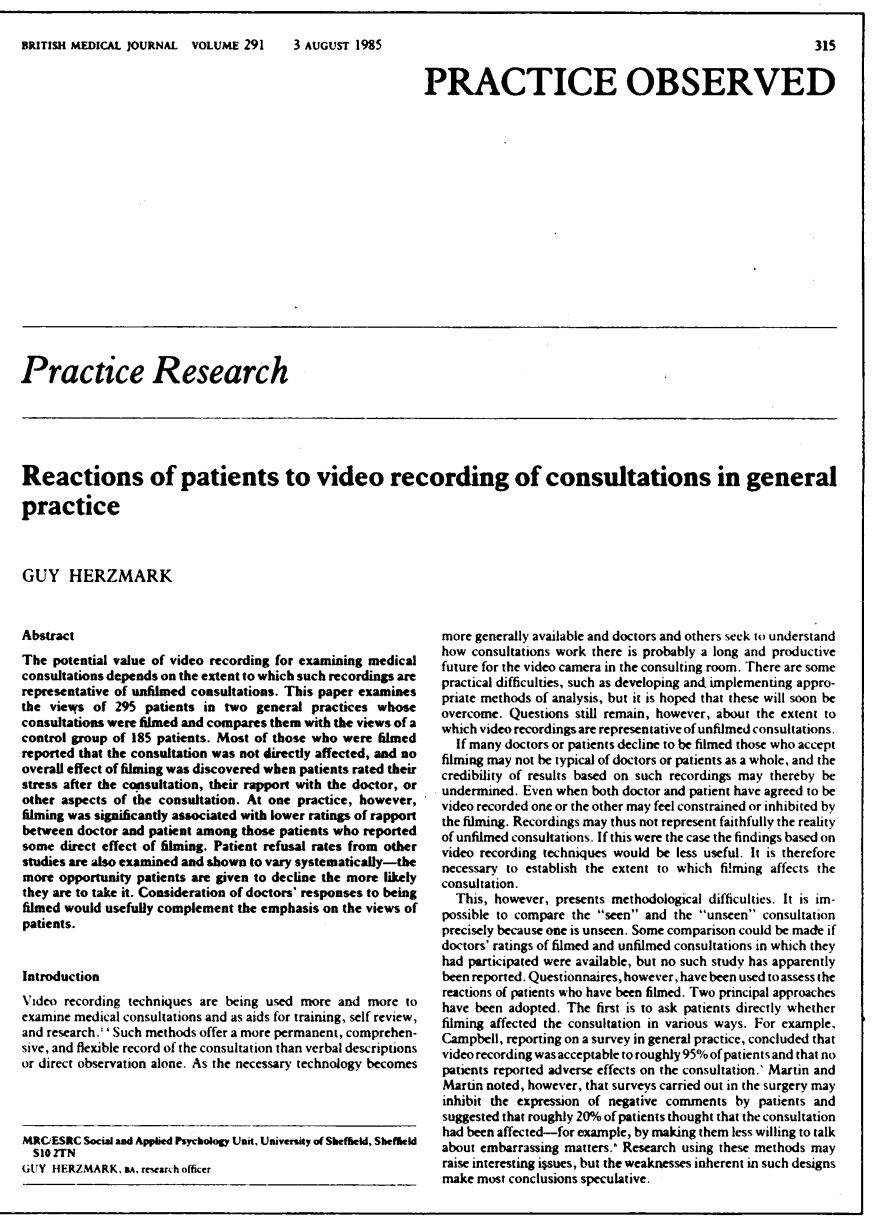
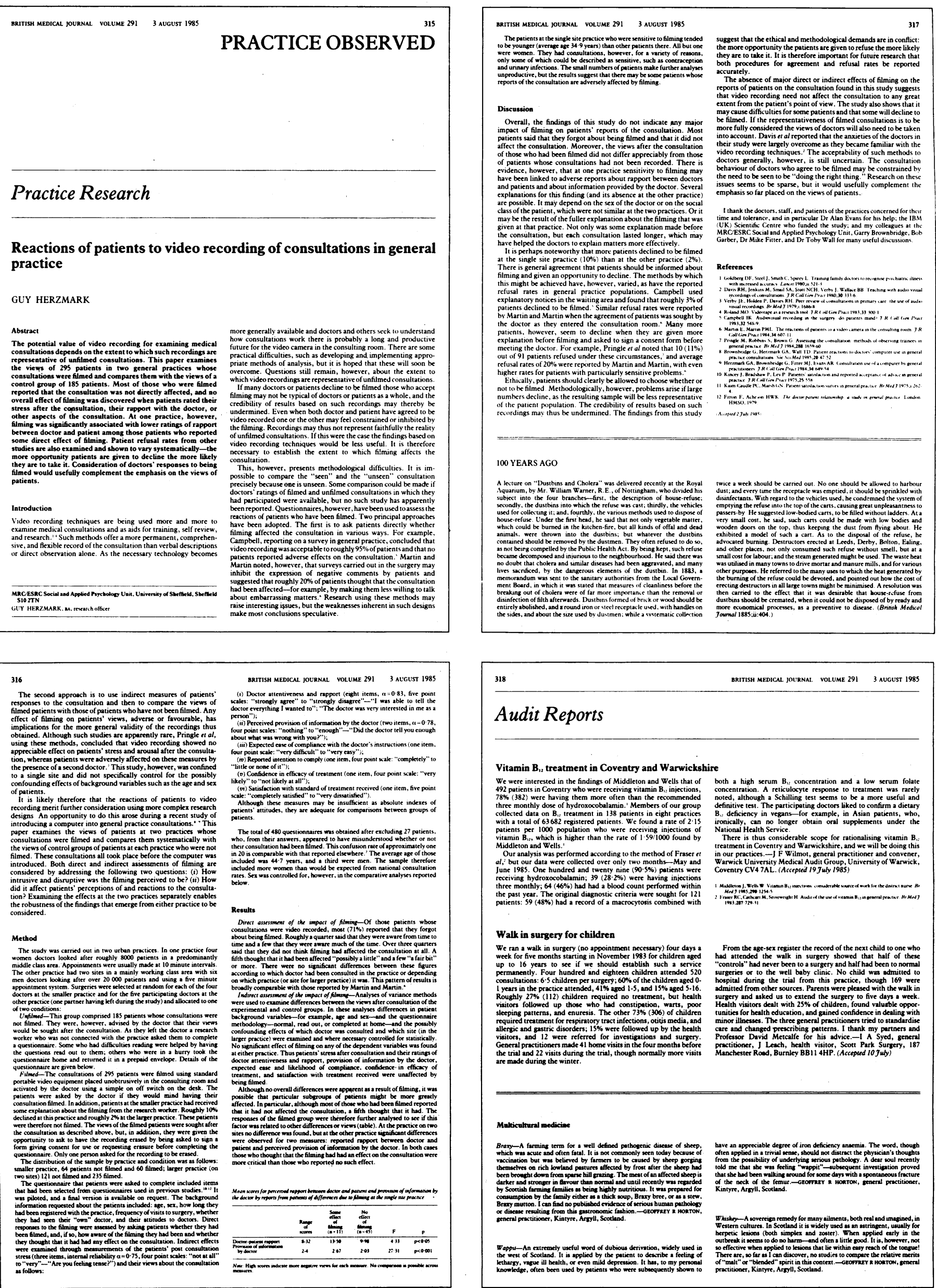

318

\section{Audit Reports}

Vitamin $B_{12}$ treatment in Coventry and Warwickshire

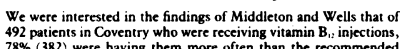

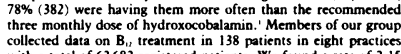

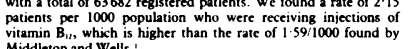
Our analysis was performed according to the method of Fraser et
at; but our data werc collected over only two months--May and
Junee

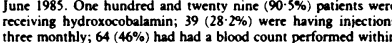
three monthly; 64 (4) (46\%) had had a blod coun performed within
the past year. The orignal diagnostic criteria wert sought for 121
patients: 59 (48\%) had a record of a macrocytosis combined with

BRTTISH MEDICAL JOURNAL VOLUME 2913 A AUGUST 198

\section{Walk in surgery for children}

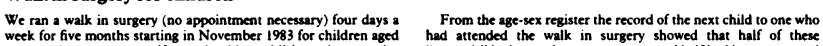

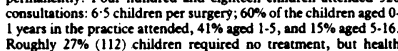

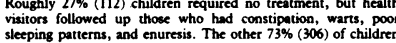

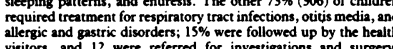

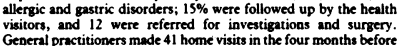

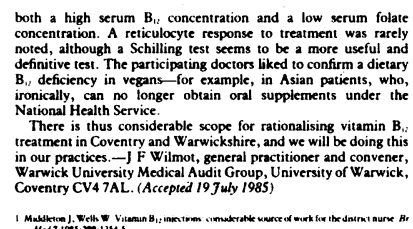

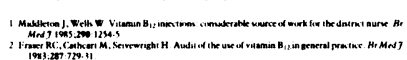

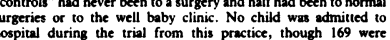
hospital during the trial from this practice, though 169 werc
admitted from other sources. Parents were plased with the walk in surgery and asked sus so extend the surgery to five days a week.
Health visitors dealt with $25 \%$ of children, found valuastle opporWunities for health education, and gained confidence in dealing with
ninor illoceses. The throe

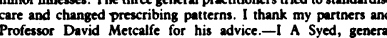

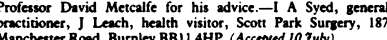

\begin{tabular}{ll} 
\\
\hline \hline
\end{tabular}

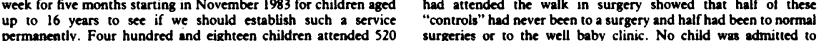

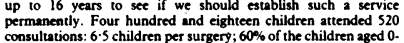
General praccitioners made 1 home visits in the four months before
the riial and 22 visists during the trial, though normally more visits 